\title{
A COMPARATIVE STUDY OF ANTHROPOMETRIC PARAMETERS OF INFANTS \&THEIR MOTHERS IN WESTERN RAJASTHAN POPULATION
}

Rekha Parashar, D.S. Chowdhary, Dhiraj Saxena, Navneet Parashar, Rohin Garg, Neha Saini

1. Senior Demonstrator. Department of Anatomy, S.M.S. Medical College, Jaipur.

2. Prof and Head, Dept. of Anatomy, Mahatma Gandhi Medical College Jaipur.

3. Associate Professor, Dept of Anatomy, S.M.S Medical College, Jaipur

4. Assistant Professor, Dept of Surgery, Government Medical College Kota.

5. Resident, Dept of Anatomy, SMS Medical College Jaipur.

6. M.Sc Anatomy, SMS Medical College

\section{CORRESPONDING AUTHOR:}

Mrs. Rekha Parashar,

918, Shanty Nagar,

Opp. Durgapura railway station,

Jaipur-3032018.

E-mail: lineparashar1985@gmail.com

ABSTRACT-AIMS AND OBJECTIVE: Growth of whole body is an integrated \& composite process. Pregnancy is one of the most critical and unique period in a women's life. The aim of present study is to determine the factors which are associated with size and proper maturity at birth in a chart if term infants to investigate their growth \& development and find out the relationship between the infants anthropometric parameters and maternal parameters. MATERIAL AND METHODS: present study was conducted on 200 newborns, out of which 100 were of normal birth weight and 100 were of low birth weight. Measured parameters of infants were Head and Chest circumference, Birth weight, Head length ratio, Ponderal Index, and Gestational age. Maternal parameters were age of mother, number of antenatal visits, weight gain from 20 weeks to late pregnancy, haemoglobin and height of mother. Results: observation shows that except age of mother, height of mother and head length ratio all parameters are significantly related.

KEYWORDS: Head circumference, Chest circumference, Antenatal visits, Haemoglobin, Ponderal Index, Head Length ratio.

INTRODUCTION: Pregnancy is one of the most critical \& unique period in a women's life. There are certain general principle which simplify its study. Growth \& development is a continuous process from conception till maturity. Estimation of anthropometric parameters of infants \& their mother are the simplest indices of development \& behaviour deficits. The analysis of anthropometric parameters of newborn is a key stone ijn the clinical work up of maturity and immaturity of new borns. A Taksande (1) et. al. in 2000 , find out the best simple anthropometric parameters for identifying low birth weight babies. Birth weight, thigh circumference, mid-arm circumference, calf circumference and head circumference had a significant relationship. Eltahir M (3) in 2005, in Sudanese newborn infants showed that birth weight was having a positive correlation with maternal anthropometric measurements.

The present study has been conducted on newborns and their mothers of Western Rajasthan in Dr.S.N.Medical College Jodhpur and SMS Medical College, Jaipur.

Material and method-This study was conducted on 200 newborn babies

The subjects were further divided in to 2 groups:- 
1. Group1-Normal birth babies having the weight of $>2500$ grams.

2. Group2-Low birth weight babies having the weight of $<2500$ grams.

Only the full term babies belonging to mothers of age between 18 to 35 years were included as a subject for the study.

\section{Measurements of infants-}

1. Head circumference- measured by a tape from supraorbital ridge anteriorly and external occipital protuberance posteriorly.

2. Chest circumference -measured at the level of nipple of baby.

3. Birth length-by measuring board.

4. Head length ratio- ratio of head circumference and length of baby.

5. Gestational age- calculated from antenatal card of mother

6. Birth weight- by detecto baby balance.

7. Ponderal Index- $\left(\mathrm{g} / \mathrm{cm}^{3}\right)$ Weight of baby / Length ${ }^{3} \mathrm{~cm}$.

\section{Maternal Measurement-}

1. Age of mother

2. Number of antenatal visits

3. Weight gain from 20 weeks to late pregnancy $(\mathrm{kg})$.

4. Haemoglobin

5. Height of mother.

\section{Observation -}

1. Showing Antenatal \& Maternal measurements-

\begin{tabular}{|c|c|c|c|c|}
\hline \multirow[t]{2}{*}{ S.NO. } & \multirow{2}{*}{$\begin{array}{ll}\text { ANTENATAL } & \text { AND } \\
\text { MATERNAL } & \\
\text { MEAUSUREMENTS } & \end{array}$} & \multicolumn{2}{|l|}{ GROUP OF SUBJECT } & \multirow{2}{*}{$\begin{array}{l}\text { STATISTICAL } \\
\text { ANALYSIS }\end{array}$} \\
\hline & & $\begin{array}{l}\text { NORMAL BIRTH } \\
\text { WEIGHT } \\
\text { (Mean + S.D.) }\end{array}$ & $\begin{array}{l}\text { LOW BIRTH } \\
\text { WEIGHT } \\
\text { (Mean + S.D.) }\end{array}$ & \\
\hline 1 & Age of mother (years) & $25.5 \pm 3.138$ & $25.3 \pm 3.352$ & $\begin{array}{l}t=1.023 \\
P>.05(N S)\end{array}$ \\
\hline 2 & No. of Antenatal visits & $4.46 \pm 1.019$ & $3.95 \pm .8572$ & $\begin{array}{l}\mathrm{t}=3.530 \\
\mathrm{P}<.01(\mathrm{VS})\end{array}$ \\
\hline 3 & $\begin{array}{l}\text { Weight gain from } 20 \\
\text { weeks to late pregnancy } \\
(\mathrm{Kg})\end{array}$ & $4.31 \pm 1.021$ & $3.35 \pm .9574$ & $\begin{array}{l}\mathrm{t}=6.832 \\
\mathrm{P}<.001(\mathrm{HS})\end{array}$ \\
\hline 4. & Haemoglobin (gm/dl) & $10.73 \pm .921$ & $9.9121 \pm 1.214$ & $\begin{array}{l}t=5.370 \\
P<.001(H S)\end{array}$ \\
\hline 5. & Height of mother $(\mathrm{cm})$ & $156.665 \pm 3.13823$ & $156.215 \pm 3.774432$ & $\begin{array}{l}\mathrm{t}=.917 \\
\mathrm{P}>.05(\mathrm{NS})\end{array}$ \\
\hline
\end{tabular}

\section{Showing the neonatal measurements-}




\begin{tabular}{|c|c|c|c|c|}
\hline \multirow[t]{2}{*}{ S.NO } & \multirow{2}{*}{$\begin{array}{l}\text { NEONATAL } \\
\text { MEAUSUREMENTS }\end{array}$} & \multicolumn{2}{|l|}{ GROUP OF SUBJECT } & \multirow{2}{*}{$\begin{array}{l}\text { STATISTICAL } \\
\text { ANALYSIS } \\
\end{array}$} \\
\hline & & $\begin{array}{l}\text { NORMAL BIRTH } \\
\text { WEIGHT } \\
\text { (Mean + S.D.) }\end{array}$ & $\begin{array}{l}\text { LOW BIRTH } \\
\text { WEIGHT } \\
\text { (Mean + S.D.) }\end{array}$ & \\
\hline 1 & Head Circumference & $32.35 \pm 1.44$ & $29.16 \pm 1.65$ & $\begin{array}{l}\mathrm{t}=14.15 \\
\mathrm{P}<.001(\mathrm{HS})\end{array}$ \\
\hline 2 & Chest Circumference & $29.71 \pm 1.27$ & $26.7 \pm 1.61$ & $\begin{array}{l}t=14.6 \\
P<.001(H S)\end{array}$ \\
\hline 3 & $\begin{array}{ll}\text { Ponderal } & \text { Index } \\
(\mathrm{gm} / \mathrm{cm} 3) & \end{array}$ & $.226955 \pm .0145$ & $.2044 \pm .0213$ & $\begin{array}{l}\mathrm{t}=8.71 \\
\mathrm{P}<.001(\mathrm{HS})\end{array}$ \\
\hline 4. & Head Length Ratio & $.6304 \pm .0509$ & $.62369 \pm .2271$ & $\begin{array}{l}t=1.20 \\
P>.05(N S)\end{array}$ \\
\hline 5. & Gestational (age weeks) & $37.84 \pm 1.361$ & $36.09 \pm 1.295$ & $\begin{array}{l}\mathrm{t}=9.32 \\
\mathrm{P}<.001(\mathrm{HS})\end{array}$ \\
\hline 6. & Birth weight (kg) & $3.0067 \pm .33544$ & $2.0897 \pm .35553$ & $\begin{array}{l}\mathrm{t}=18.76 \\
\mathrm{P}<.001(\mathrm{HS})\end{array}$ \\
\hline 7. & Length $(\mathrm{cm})$ & $50.94 \pm 1.54932$ & $46.67 \pm 2.6364$ & $\begin{array}{l}\mathrm{t}=14.6 \\
\mathrm{P}<.001(\mathrm{HS})\end{array}$ \\
\hline
\end{tabular}

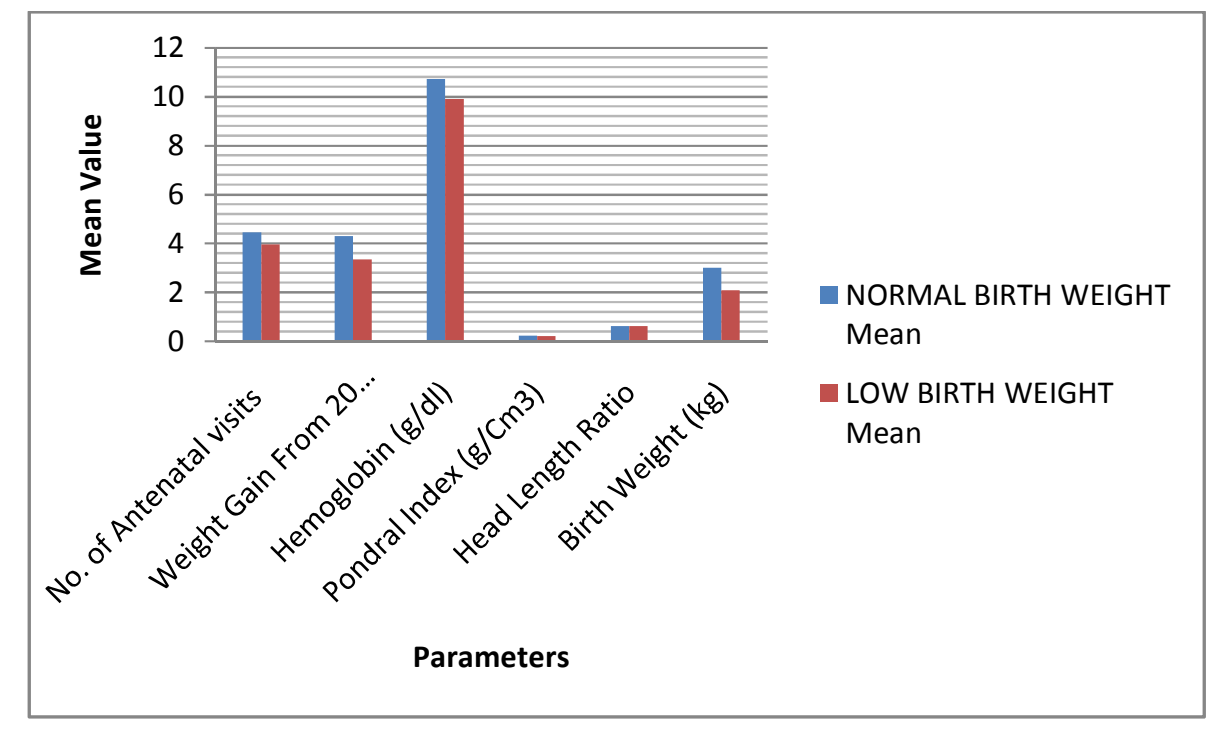

*Graphic comparison of antenatal \& maternal measurements of normal birth weight \& low birth weight mothers 


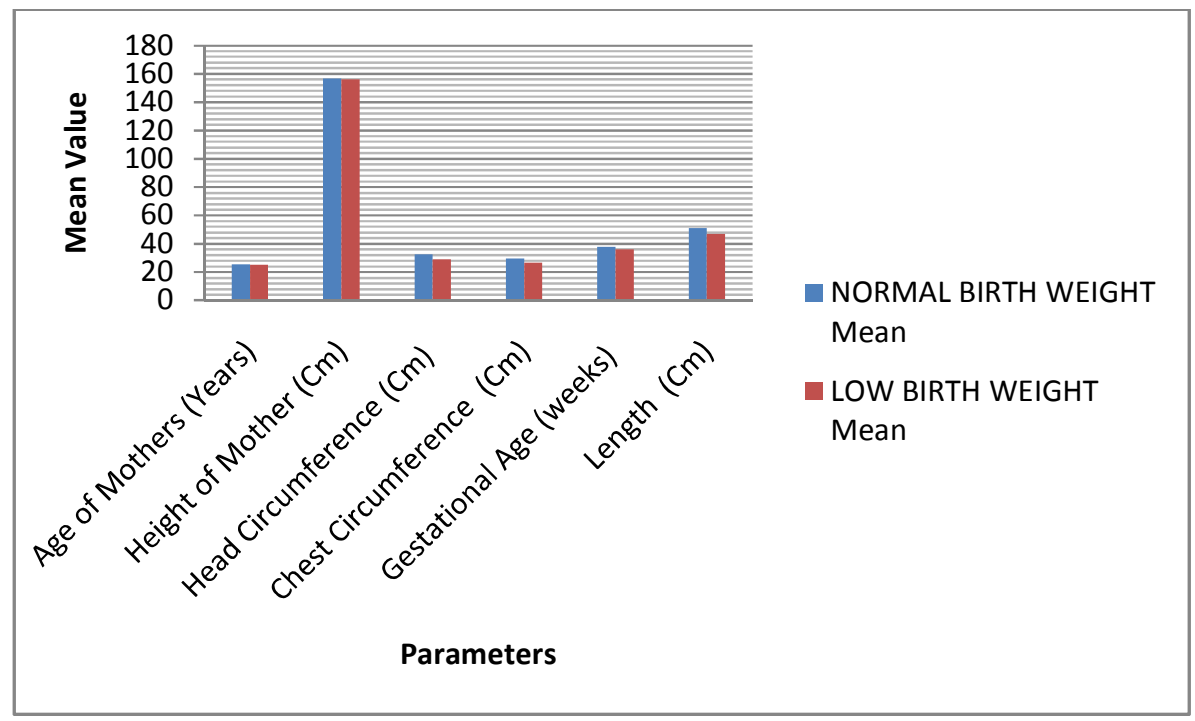

\section{*Graphic comparison of neonatal measurements of normal birth weight \& low birth weight babies}

DISCUSSION: The present study has been undertaken to establish the relationship between various anthropometric parameters of newborns and their mothers in Western Rajasthan population. The study was conducted on 200 neonates born within 48 hours of birth, out of which 100 are of normal birth weight infants, ( $\geq 2500 \mathrm{gms})$ and 100 of low birth weight infants, ( $\leq 2500 \mathrm{gms}$ ). Considered parameters of new borns were head circumference, chest circumference, Ponderal index, head length ratio, Gestational age, birth weight and birth length of infants. The observed parameters of mothers are number of antenatal visits, height of mother, haemoglobin, weight gain from 20 weeks to late pregnancy.

Average age of mother was $25.5 \pm 3.359$ years for the normal birth weight infants and $25.3 \pm 3.359$ years- For the mother of low birth weight infants $\mathrm{P}>0.05$ shows non significant relationship E. Karim (4) et.al. in 1997 observed that low birth weight babies were more common in younger $(<20$ years) and older ( $>30$ Years) mothers.

Value for height of mothers was observed $156.665 \pm 3.3182 \mathrm{~cm}$ for normal birth weight and it was $156.215 \pm 3.17744 \mathrm{~cm}$ for the mother of low birth weight infants. $\mathrm{P}>.05$ shows no significant relationship. Elthair M. (3) et.al. in 2005 concluded that maternal height which is less than $56 \mathrm{cms}$ increases the risk of low birth weight infants.

Observed value of gestational age for normal birth weight infants was (37 \pm 1.361 ) weeks and $(36.09 \pm 1.295)$ weeks for low birth weight infants. P value is $<.001$ shows highly significant relationship. Elthair M (3) et.al. in 2005 showed that there is a significant relationship of gestational age with height of mother.

Average value of haemoglobin for mothers of normal birth weight infants was $10.73 \pm .092(\mathrm{gm} / \mathrm{dl})$ and $9.919 \pm 1.214(\mathrm{gm} / \mathrm{dl})$ for the mothers of low birth weight infants. P value $<.001$ shows highly significant relationship in our study. Murphy J.F.et.al. ( 9) in 1986 showed the relation between haemoglobin concentration and birth outcomes. They reported that both $(>13.2 \mathrm{gm} / \mathrm{dl})$ and low $(<10.4 \mathrm{gm} / \mathrm{dl})$ values of haemoglobin were associated with adverse outcome. Mothers having the intermediate range of haemoglobin (10.4- $13.2 \mathrm{gm} / \mathrm{dl}$ ) fared best. 
Calculated value of head circumference in the present study is[32.35 \pm 1.44$] \mathrm{cm}$ for the normal birth weight infants and[29.16 \pm 1.65$] \mathrm{cm}$ for low birth weight infants. $\mathrm{P}$ values $<.001$ shows highly significant relationship. Lenkaye et al[8] in 1961 recorded the mean value of head circumference as $33.25 \mathrm{~cm}$ in his New Delhi study for full term babies.

In our present study calculated mean value for chest circumference for normal birth weight infants is[29.17 \pm 1.27$] \mathrm{cm}$ and $[26.7 \pm 1.61] \mathrm{cm}$ for low birth weight infants. P value $<0.001$ shows highly significant relationship. Ian. D. Diamond[7]et al in 1991 showed in their study that chest circumference was $30 \mathrm{~cm}$ for normal birth weight babies.

Calculated average value of length of the baby is [50.94 \pm 1.54932$] \mathrm{cm}$ for normal birth weight babies. $P$ value is $[46.67 \pm 2.6364] \mathrm{cm}$ for low birth weight babies. P value is $<.001$ shows highly significant relationship. Fazul Hugue[5] in1961 calculated the mean value of birth length for normal birth weight infants was $52 \mathrm{~cm}$ in Bangladesh.

Average mean value for birth weight in our study is (3.0067 \pm .3354$) \mathrm{kg}$ for normal birth weight infants and it is $(2.0897 \pm .3553) \mathrm{kg}$ for low birth weight babies. P value is $<.001$ showing highly significant relationship. Elthair (3) in 2005 in Sudanese new born infants showed that birth weight was having a positive correlation with maternal anthropometric measurements.

Average value for antenatal visits of mothers of normal birth weight babies is $(4.46 \pm 1.019)$ and it is $(3.95 \pm 0.8572) \mathrm{kg}$ for the mothers of low birth weight babies. P value is $<.01$ shows very significant relationship in our study. Herbest et.al. (6) in 2003 observed that no prenatal care was associated with preterm birth and low birth weight infants.

Mean value calculated for weight gain form 20 weeks to late pregnancy is $(4.31 \pm 1.28) \mathrm{kg}$ for the mothers of normal birth weight infants and it is $(3.35 \pm 0.9574) \mathrm{kg}$ for mothers of low birth weight infants. P value is < .001 showing highly significant relationship. Dawes , M.G. et.al. (2) in 1991 showed that mean maternal weight gain of initial visit was 140 pounds. Average weight gain per week was observed 0.8 pounds. Highest weight gain were observed during weeks 16 to 24 and 32 to 36 weeks of pregnancy. Study of various anthropometric parameters of new borns and their mothers are of prime significance in establishing the proper development. Total studied subjects are 200 neonates born within 48 hours, out of which 100 are of normal birth weight infants ( $\geq 2500$ gms ).

Antenatal visits of mothers show very significant relationship. Weight gain during pregnancy, haemoglobin concentration, head circumference, chest circumference, ponderal index , gestational age, birth weight and mean value for the length of the baby in infants shows highly significant relationship while age of mother, height of mother and head length ratio shows non significant relationship.

So strength of the study clearly dictates the importance of above parameters in the assessment, management of premature babies and in prognosis regarding the survival of premature and growth retarding babies.

All the measured parameters for the study was according to the standard criterion given in reference text books.

\section{REFERENCES:}

1. A . Taksande, K.Y. Viherker, P. Chaturvedi, S. Gupta and P. Deshmukh , 2000, Prediction of low birth weight babies by anthropometry . Journal of tropical Peadiatrics.

2. Dawes , M. G. Grudzinskas J.G. 1991; patterns of maternal weight gain in pregnancy. British Journal of Obstetrics and Gynaecology 1991, 0306-5456. 
3. Eltahir M.Elshibly Gerd Schmalisch, Sept 2005, The effect of maternal anthropometric characteristics and social factors on gestational age and birth weight in Sudanese new born infants , Vol. 95 ,No. 9, American Journal of Public health 1545-1551.

4. E Karim, C.G.N. Mascie -Taylor 1997, Annals of human biology, vol 24 issue 5 october , pages 387-401.

5. Fazul H. , Zakir Hussain A.M. (1991); Detection of low birth weight newborn babies by anthropometric measurements in Bangladesh. Indian Journal of Paediatrics ; 58:223, 1991

6. Herbest MA, Mercer BM, Beazley D, Meyer N, Carr T. 2003, Relationship of Prenatal care and perinatal maturity in low birth weight infants , Am. J. Obstet Gynecol 189; (4): 9303.

7. Ian D. Diamond, Ali M. Abd El-Aleem, M.Y. Ali , S.A.M. Mostafa, S.M.A. El-Nashar and R.T. Guidotti 1991, Relationship between birth weight and arm and chest circumference in Egypt , Journal of Tropical Paediatrics 37 (6): 323-326.

8. Lanskay J (1961): The relationship between length of gestation birth weight and certain other factors. Child health org. 26: 183, 1961.

9. Lt. Col G Singh, Capt R Chauhan, Maj K Sidhu, 2009 Maternal Factors for Low Birth Weight babies. MJAFI, Vol, 65, No. 1

10. Murphy JF, O.Rirordan J, Newcombe RG, Coles EC, Pearson JF 1986, Relationship of haemoglobin level in first and second trimester outcome of pregnancy Lancet May 3;1 (8488): 992-5. 